\title{
Board Certified Physicians in Health Informatics A European Precedent for Professional Recognition
}

\author{
F.H. Roger France', Cl. Beguin', Ch. Mélot ${ }^{2}$, P. Gillet ${ }^{3}$ \\ ' Université Catholique de Louvain \\ 2 Université Libre de Bruxelles \\ ${ }^{3}$ Université de Liège
}

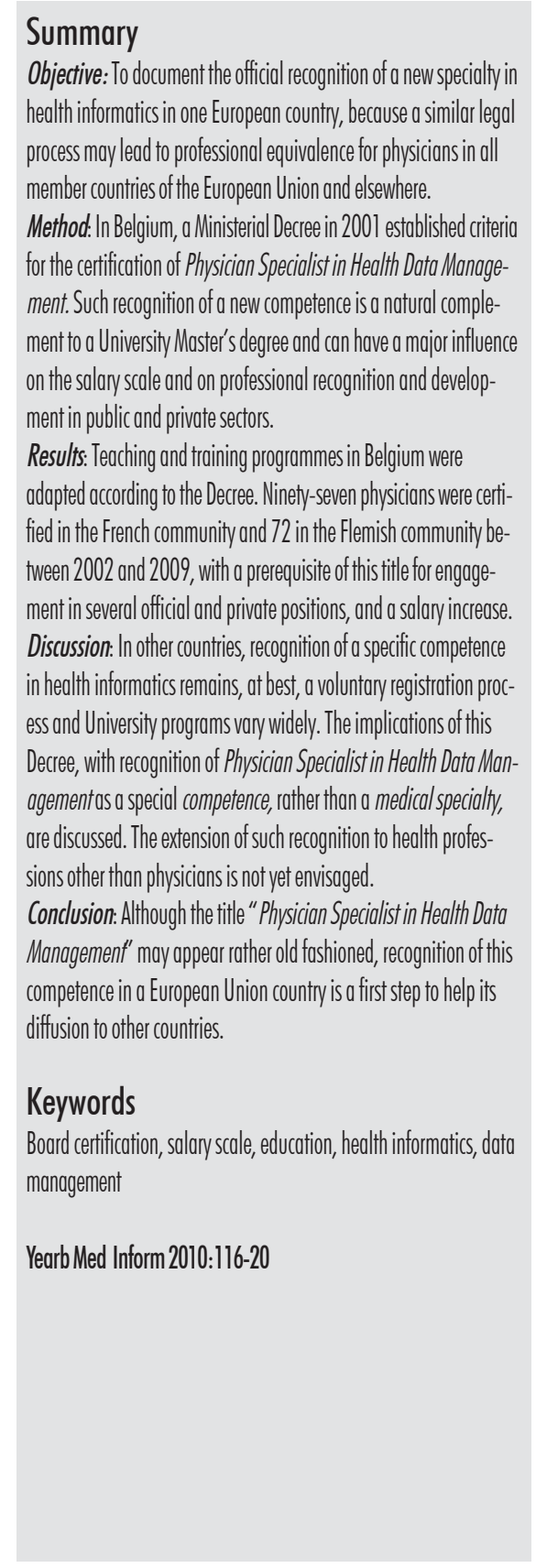

\section{Introduction}

New professions have to follow several steps in order to be recognized by society. An important first step for a new discipline, like health informatics, is to be recognized by universities and offered as a training program. Having a degree is, however, not sufficient. Employment is the next step, most often based on the academic titles achieved, and associated with a salary scale. Such professional recognition necessitates that the discipline in question is endorsed by the state by means of presentation in the official journal that publishes laws and describes professional qualifications and functions.

Computer scientists can have various levels of training, university or nonuniversity degrees, particular interests and skills. They may be employed as analysts, programmers, or team managers, for systems development, network management, data analysis, artificial intelligence, computerized assisted learning, modelling, etc. In most countries, recognition by the State of new professions with details of qualifications, functions and salary scale appears to be a prerequisite for societal acceptance.

Universities in many countries offer educational programs in health informatics, such as that promoted by the IMIA (International Medical Informatics Association) [1], leading to degrees for physicians. However, there is no globally recognized qualification and a great variety of different courses and jobs exist. Without official recog- nition of this new professional category, physicians involved in health informatics may be confronted by employment vulnerability, professional variability, and random requirements in education and training.

The publication of a Ministerial Decree [2] in 2001 in Belgium, state member of the European Union (EU), establishing criteria for the recognition of "Physician Specialist in Health Data Management" represents a step forward to Board certification, and was based on the classical procedure of recognition that is applied to all specialties within medicine. This legal precedent in Belgium serves as an example to acknowledge the existence of a new special competence in the EU. It opens the way for professional equivalence in any other EU state member, following Directive 2005/36/CE [3], and may encourage other countries to follow suit.

\section{Method: a Ministerial Decree on Certification Criteria}

\section{A Legal Procedure}

On 15 October 2001, the Parliament of Belgium voted in a Ministerial Decree that had been presented by Mrs M. Alvoet, Minister of Public Health, and which fixed criteria for certification of Physician Specialist in Health Data Management. This Decree was published in the Official Journal (Le Moniteur Belge - Belgisch Staatsblad) on 13 December 2001 [2]. It has been 
integrated into Board Certification procedures for recognition of physicians (either specialists or general practitioners), in agreement with the law defining professional titles for health care professionals.

\section{Health Data Warehousing and Management}

Three categories of health data have been defined by the Decree:

- personal patient data: medical history, clinical data, results of tests and procedures (medico-technical data), diagnoses, treatments, and socioeconomic items;

- epidemiologic data in relation to the physical or mental status of healthy or ill populations, linked or not to a disease or pathogenic agent, environmental or socio-economic context

- data related to health care systems: costs and efficiency of health care interventions and global programs of health intervention.

Health data warehousing and management includes data collection (input), storage, transfer through secured networks, coding, data analysis and use of results, as well as the development of appropriate tools.

\section{Education and Training Criteria}

The following certification criteria are required in order to certify a Physician Specialist in Health Data Management qualification:

The candidate should:

- hold a legal diploma of medical doctor (following conditions described in the Royal Decree $n^{\circ} 78$ art. 2 of 10 November 1967) and have completed at least two years' clinical experience;

- OR be a general practitioner or a physician specialist, holding one of the specific professional titles reserved for health care professionals, including dental practice;
- AND have obtained a particular competence in health data management that follows the criteria described hereafter.

The title of Physician Specialist in Health Data Management can only be attributed if the candidate has followed a special training period of at least two years, including:

1. A specific university postgraduate course for at least one full-time year on the following topics:
(a) informatics, telematics, database management;

(b) statistics and epidemiology;
(c) diagnosis, treatment and pathol- ogy coding;

(d) medical data registration;
(e) health economy, management and communication principles;

(f) health care organization in Belgium and in other countries;
(g) Belgian and international laws on personal data protection and on experimental clinical research;

(h) laws on hospitals in Belgium;

(i) health intervention programs and diseases global management;

(j) quality assurance programs.

2. A practical training period (stage) of at least one full-time year in one or several certified training centres. For a specialist candidate, this training practice can be combined with a training program in any discipline recognized by the Royal Decree of 25.11.1991 on medical specialties.

3. Publication or presentation to a jury of specialists of an original dissertation concerning health data management.

\section{Maintenance Criteria}

In order to remain accredited, physician specialists in health data management must prove at regular time intervals that they are maintaining and improving their knowledge in the area of health data management, and are contributing to publications at an appropriate level on health data management or on the development of tools to manage health data.

\section{Transitory Measures}

For two years after the date of publication of the Ministerial Decree (M.D. of 13 December 2001), every physician who worked primarily in health data management or in developing tools therefore, who had contributed to scientific work in this area and could demonstrate sufficient knowledge in the courses described under the educational criteria section above, could obtain the title of Physician Specialist in Health Data Management, provided they introduced their candidacy to the ad hoc Certification Board.

For one year after the publication of the Ministerial Decree, a period of practical or theoretical training that had already started and was being pursued could be taken into account.

\section{Training Supervision and Training Centres}

The Decree specifies that the supervisor of the trainee ("Maître de stage") should be a Physician Specialist in Health Data Management. Any hospital, research or administrative unit in which the main activity is to manage medical data using an appropriate infrastructure in informatics and telematics can be certified as a "training centre".

\section{Results}

\section{Creation of Certification Boards}

In 2002, two Boards were created by the Federal Public Service (FPS) of Public Health, one for French-speaking, the other for Flemish-speaking candidates, to examine whether candi- 
dates fulfill certification requirements for the title of Physician Specialist in Health Data Management. The Minister of Public Health appointed ten members to each of the Certification Boards, selected from lists of candidates proposed by Universities and physicians' professional unions. Each Board elected a chairman (F. Roger France for the French and G. De Moor for the Flemish Board), while the FPS of Public health nominated civil servants as Secretaries.

\section{Regulations for Training Practice}

The two Boards agreed on criteria for training practice, taking into account requirements existing in other specialties.

\subsection{Trainee Supervision:}

Each training supervisor should be a Board certified Physician Specialist in Health Data Management. Their mandate is for 5 years, with possible renewal on request by the candidate. He/ she should have at least 8 years' experience (continuous active practice) in health data management, be actively involved in teaching activities, have established peer notoriety, and have achieved several publications in international journals. He/she should be recognized as having responsibility for trainees in the agreed service, and should be employed on an open-ended contract in his/her institution. He/she should commit him/ herself for the time needed to train the candidate and should have at least one part-time collaborator, board certified in the specialty, with at least 5 years' experience and actively present on the training field. The training supervisor may be responsible for a trainee located in a training centre other than his/her agreed service, on the condition that the certification Board agrees and another supervisor, who agrees to collaborate, is present at least half of the time at the other location.

\subsection{Training Centre Recognition Criteria}

A hospital, research, or administrative unit mainly involved in the management of medical data, using an appropriate infrastructure in informatics and telematics, can be accepted as a "training centre", under the following conditions:

- a trainee supervisor has to be appointed by the training centre;

- the activity of the service should correspond to at least one of the domains listed in the required topics for the education program to become a specialist

- the number of trainees should be limited to 3 to 4 maximum, depending on the capacity of the centre to adequately follow candidate training.

\subsection{Training Program}

Each candidate for the specialty training must present an agenda ("plan") for their training work and an "education program", signed by the training supervisor and submitted to the certification Board during the first three months of the training period.

\subsection{Training Reports}

A "training report book", as defined by the certification Board, has to be transmitted at the end of the training period, with comments from the training supervisors, designed to estimate how far candidates have satisfied their obligations.

A "training evaluation report" describing qualitative and quantitative aspects of the work must be written by the candidate and transmitted to the certification Board after the training period. These training evaluation reports will provide indicators for the regular evaluation of training supervisors and agreed centres.

\subsection{Insurance, Working Contract and Salary of Trainees}

The trainee should be covered by professional liability insurance taken out by the employer, as well as for accidents and health care. He/she should have a written contract specifying working conditions as well as legal and financial aspects. The candidate should be paid in relation to the work done, and the salary has to be communicated to the certification Board.

\section{Board Certification}

Between 2002 and 2009, 164 of around 200 candidates have been certified by the Boards and nominated by the Federal Minister of Health for the title of Physician Specialist in Health Data Management: 92 in the French section and 72 in the Flemish section.

All physicians who wish to be recognized as Physician Specialists in Health Data Management now have to obtain a Master Degree in health data management that is offered by all Universities that have a Faculty in Medicine, to propose a training work program to the certification Board and to complete it, and to publish an original work on a relevant topic.

\section{Salary Scale Improvement}

Official recognition of the title of Physician Specialist in Health Data Management had an immediate consequence for physicians working in public services in Belgium. Their salary scale increased. The title was also recognized in the private sector;

This new competence is unusual in medicine, because it is not a clinical specialty. Therefore, a Physician Specialist in Health Data Management does not need to have a number attributed for reimbursement of procedures as other specialists do in Belgium. However, he/she may already be a general practitioner or a clinical specialist with a supplementary "special competence" in Health informatics. In such cases, payment will depend on the different activities, financed by various sources. 


\section{Reorganization of University Programs in Health Informatics}

Curricula in Health informatics have had to be adapted in all Belgian Universities where a Masters' degree already existed. Publication of the Ministerial Decree was followed by an improved homogeneity in the topics required for the professional recognition, although optional topics vary among the different Universities.

\section{Employment Projections and Number of Students to Register}

The French certification Board estimated the number of positions to fill as between 100 and 160 in the Frenchspeaking Community (Wallony and Brussels), including 60 to 120 hospital posts and 40 posts outside hospitals, with a length of 20 years as a mean for their career (of maximum 40 years).

For the three French-speaking Universities (ULB Brussels, ULg Liège, UCL Louvain), five new positions per year are foreseen (100/20); which requires enrolment of six students a year, or two per University.

\section{Discussion}

It is important that other countries are aware of the process by which the title of Physician Specialist in Health Data Management was recognized by the public authorities in Belgium in 2001 [2], because any physician who has successfully completed the education curriculum described, completed a training period in health informatics for more than a year, and published an original paper in this field in an international journal could ask for equivalence of the degree title in their own country if within the EU [3]. The procedure completed by Belgium for recognition of this post may also inspire other countries to do the same.
To our knowledge, Belgium is the first country to have recognized this new specialty for physicians through a Board Certification by an official Decree. Elsewhere, it remains, at best, a voluntary registration process.

In the United States, AMIA and AMA currently work to the creation of a medical specialty in clinical informatics [4]. It is interesting to see that the proposal involves also a "Clinical Infor-matics Board Certification" that follows the US procedures in order to recognize a new competence in a new subspecialty in medicine.

Professional Associations in various countries propose criteria available on the web, like COACH (Canadian Health Informatics Association) [5, 6], UKCHIP (United Kingdom Council for Health Informatics Professions) [7, 8] or UIC (University of Illinois Chicago) [9], but this process is voluntary and does not have the strength of a text of law approved by Parliament to adapt salary scales, titles, and University curricula.

In France, partial recognition exists in the context of the PMSI (Programme de Médicalisation des Systèmes d'Information), as physician positions, qualifications and functions in a DIM (Département d'Information Médicale) have been officially described since 1982, but the role of these health professionals has been restricted to hospital data management linked to billing data. Furthermore, in 2007, a change in the French hospitals funding method has restricted the job of the DIM to billing and accounting, very administrative tasks.

The lack of recognition of this profession has generated so much dissatisfaction that these physicians set up a professional union on 22021988 (SYNADIM: syndicat national des médecins du DIM) to defend their rights [10]. DIM professionals working in Health data management in France wish to be recognized as physicians, with medical doctors' tasks, rather than with only administrative work. They look for a public health enlarged mandate in their country.
The choice of the title "Physician Specialist in Health Data Management" is somewhat regrettable as it appears rather old-fashioned compared to "specialist in health informatics", but this alternative terminology is not easily understood by the lay-public, and the proposed title was accepted by the Parliament.

The "Superior Council of Physician Specialists" of the FPS of Public Health asked certification Boards if this new title had to be considered as a full specialty or as a special competence. As it can be combined with a clinical specialty, like surgery or internal medicine, or with general practice, the Council decided that it is "special competence" rather than a specialty in its own right and arguments in favour of physicians working only in health informatics were not retained. Insertion in another specialty, like public health, could not be done because this title is not yet recognized in Belgium. The present status, however, is a step forward using Board certification and is based on the classical procedure of recognition applied to all specialties in medicine. Its extension to professions other than physicians is not yet under consideration.

\section{Conclusion}

Obtaining a university degree is not on its own enough [11, 12]; degrees should lead to employment with official recognition of professional titles linked to a salary scale.

The Ministerial Decree of 15 October 2001 in Belgium [2] is a step forward that can lead to professional equivalence in all country members of the European Union and can show other countries how to achieve professional recognition of health informatics. It has been achieved through the traditional "certification Board", as done for other medical specialties. It is very encouraging to learn that a similar approach is in progress in the USA [4]. 
Its publication had an effect on the development of health informatics academic pograms in Belgium, by stimulating a Master Degree availability in all Faculties of Medicine, by enforcing a better uniformity in the basic courses to be teached, and by giving incentives to group courses between different universities, leading to common inter-university diplomas, given the scarcity of resources for a limited number of students.

\section{References}

1. Mantas J, Ammenwerth E, Demiris G, Hasman A, Haux R, Hersh W, et al. Recommendations of the International Medical Informatics Association
(IMIA) on Education in Biomedical and Health Informatics. First revision. Methods Inf Med 2010;49:105-20.

2 Moniteur Belge du 13.12.2001. Arrêté ministériel du 151001 fixant les critères d'agrément des médecins spécialistes en gestion de données de santé, 2001,3555; 43044-6.

3. European Directive 2005/36/CE on recognition of professional qualifications. Official Journal $\mathrm{n}^{\circ} \mathrm{L} 255$, 30/09/2005, 0022-0142

4. Detmer DE, Munger BS, Lehmann CU. Clinical Informatics Board Certification: History, Current status, and Predicted impact on the Clinical Informatics Workforce. Appl Clin Inf 2010,1:11-8.

5. http://www.cphims.ca (The certified professional in health care information and management systems - Canada) Last access March 28, 2010

6. http://www.coachorg.com/credentials. Last access March 28, 2010

7. http://www.ukchip.org. Last access March 28, 2010

8. Roberts J. Developing the Health Informatics Professional. In: Hayes G, Barnett D, editors. UK
Health Computing: recollections and reflections. BCS, May 2008

9. http://www.global.uillinois.edu/healthcare/ certification-public-health-informatics Last access March 29, 2010-03-29

10 http://www.synadim.fr Last access March 28, 2010

11. Thayer C, Boulay F, Roger France F. European strategies for training in health information systems. Int J Biomed Comput 1991;28:117-25.

12. Roger France FH, Boulay P, Thayer C, Higgins M Solberg LK, Norman S, et al. Recommandation n $\mathrm{R}(90) 21$ relative à la stratégie de formation aux systèmes d'information de santé. Conseil de l'Europe; 1990.

\section{Correspondence to:}

Francis Roger France

Avenue Brunard, 11

B-1180 Brussels

Belgium

E-mail: frf@skynet.be 